\title{
Measuring the effect of conflict on software engineering teams
}

\author{
J. S. KARN AND A. J. COWLING \\ University of Sheffield, Sheffield, England
}

\begin{abstract}
This article describes a project that aimed to uncover the effects of different forms of conflict on team performance during the important feasibility, requirements analysis, and design phases of software engineering (SE) projects. The research subjects were master of science students who were working to produce software commissioned by real-world clients. A template was developed that allowed researchers to record details of any conflicts that occurred. It was found that some forms of conflict were more damaging than others and that the frequency and intensity of specific conflicts are important factors to consider. The experience of the researchers when using the final template suggests that it is a valuable weapon to have in one's arsenal if one is interested in observing and recording the details of conflict in either SE teams or teams in different contexts.
\end{abstract}

This article describes how observational methods were used to ascertain the effect of conflict on the performance of software engineering (SE) teams during the important feasibility, requirements analysis, and design phases of software projects, and the subsequent development of social and conflict interaction protocols to allow researchers to record conflict episodes when they occurred. Three teams consisting of master of science (MSc) students at the University of Sheffield were observed as they worked through the feasibility, analysis, and design phases of the SE life cycle. Each occurrence of conflict between team members was recorded, as well as the form and intensity of the conflict.

There were several reasons for pursuing this line of research. The first is that commercial SE is a team-based activity, and, as in other related contexts, success is dependent to a large extent on whether or not team members have succeeded in establishing a cooperative environment (Cohen \& Bailey, 1997). Additionally, several scholars have opined that the social factors of SE are potentially more important than the technical aspects (Curtis, 1991, 1998; Curtis, Krasner, \& Iscoe, 1988; Curtis, Walz, \& Elam, 1993). This view is reinforced by other scholars who hold the belief that future SE research should focus more on human factors (Crowston \& Kammerer, 1998a, 1998b; Petre, Budgen, \& Scholtz, 2004). The rationale behind this argument is that further exploration into these areas will play an important role in the maturation of SE as an academic discipline.

The importance of teamwork in SE has long been recognized at a pedagogic level. It is now common for SE degree programs to include one or more team projects. These projects should enable team members to develop what has been termed positive interdependence (Johnson \& Johnson, 1978), which theoretically should result in enhanced short-term memory, long-term retention, greater understanding of course material, and critical thinking and problem-solving skills.

Although there are numerous advantages to working in teams, there are also several problems that one needs to be aware of (Harris \& Looney, 1999). Harris and Looney stated that one of the main problems is that a team approach to a project usually generates a greater degree of conflict than many people are accustomed to. This conflict can be a serious impediment to performance.

This situation raises the question of what the exact nature of conflict actually is. Some (Amason, 1996; Galinsky, 2002; Jehn, 1995) have argued that conflict is an inevitable and pervasive aspect of organizational life. People are said to be in conflict when the actions of one person are interfering, obstructing, or in some other way making another's behavior less effective (Tjosvold, 1997).

Previous team-process research has distinguished three separate forms of conflict: task (or cognitive), relationship (or affective) (Amason, 1996; Amason \& Schweiger, 1994; Pinkley, 1990), and process (Jehn, 1995). These forms of conflict have been found to have different consequences on the performance of teams, with relationship conflict being the most damaging (Amason \& Sapienza, 1997; De Dreu, 1997; Pelled, 1996; Pelled, Eisenhardt, \& Xin, 1999).

Of more relevance to the work described in this article are those studies that looked specifically at conflict in an SE context (Elam \& Walz, 1988; P. Sawyer, Sommerville, \& Viller, 1999; S. Sawyer, 2001). An outcome of one of the aforementioned studies (Elam \& Walz, 1988) was the development of a descriptive conflict model having four dimensions: time, people, content, and process.

This model of conflict is presented in Table 1, and it was used as a starting point for the creation of the template that will be described later in the article. 
Table 1

Elam and Walz (1988) Model of Conflict

Time Frequency of conflict, concurrency of conflict, pacing of conflict

People Who's in conflict? With whom?

Content What is the conflict about?

Process To what extent are disagreements substantiated?

At what level of abstraction are they substantiated?

\section{Conflict}

Conflict is a natural disagreement resulting from individuals or teams that differ in attitudes, beliefs, values, or needs. As human beings interact in organizations, differing values and situations create tension. One prominent scholar of conflict (Deutsch, 1973) listed the following issues involved in conflicts:

control over resources;

preferences and nuisances in which the tastes or activities of one party impinge upon another;

values, when there is a claim that a value or set of values should dominate;

beliefs, when there is a dispute over facts, information, reality, and so forth; and

the nature of the relationship between the parties.

The traditional view of conflict was that it was a negative phenomenon and a serious threat to effective team performance (Deutsch, 1949a, 1949b; Robbins, 1989). However, this is not a universally held opinion amongst conflict researchers, and it has been challenged: Scholars have argued that more focus should be placed on the form the conflict takes. The point is that conflict per se need not be a negative force. Indeed, some (e.g., Amason, 1996; Darling \& Walker, 2001; Tjosvold, 1991) have argued persuasively that when positive conflict is recognized, acknowledged, and managed in a proper manner, personal and organizational benefits can accrue.

\section{Constructive and Destructive Conflict}

Conflict has been given a bad name by its association with disruption. However, as was mentioned in the previous section, several researchers have argued that conflict need not be a negative force and that it is often the case that it is the form the conflict takes that determines how much damage is caused - that is, whether it is a constructive or destructive conflict.

Constructive conflict (Desivilya, 1998; Rognes, 1998; Tjosvold, Hui, \& Law, 2001) is characterized by cooperation and flexibility. The principal focus is on trying to achieve a solution between struggling parties that is mutually satisfactory to everyone. However, destructive conflicts are more concerned with power struggles and personal antagonisms (De Dreu, van Dierendonck, \& De Best-Waldhober, 2005; Wilmot \& Hocker, 2001) and are characterized by domination, escalation, retaliation, com-

Table 2

Social Interaction Protocol

\begin{tabular}{|c|c|}
\hline Code & Name \\
\hline \multirow[t]{2}{*}{ Init } & Initiating/Contributing \\
\hline & Definition: Contributes ideas and suggestions; proposes solutions and decisions. \\
\hline \multirow[t]{2}{*}{ Inf-Seek } & Information Seeking \\
\hline & Definition: Asks for clarification of comments in terms of their factual adequacy. \\
\hline \multirow[t]{2}{*}{ Op-Seek } & Opinion Seeking \\
\hline & Definition: Asks for clarification of opinions made by other members of the team. \\
\hline \multirow[t]{2}{*}{ Inf-Giv } & Information Giving \\
\hline & Definition: Offers facts or generalizations that may relate to the team's task. \\
\hline \multirow[t]{2}{*}{ Op-Giv } & Opinion Giving \\
\hline & Definition: States beliefs or opinions having to do with suggestions made. \\
\hline H-Seek & Help Seeking \\
\hline \multirow[t]{2}{*}{ Elab } & Elaborating \\
\hline & Definition: Elaborates ideas and other contributions; offers rationales for suggestions. \\
\hline \multirow[t]{2}{*}{ Coord } & Coordinating \\
\hline & $\begin{array}{l}\text { Definition: Clarifies the relationships among information, opinions, and ideas or suggests } \\
\text { an integration of the information, opinions, and ideas of subteams. }\end{array}$ \\
\hline \multirow[t]{2}{*}{ Orient } & Orienting/Summarizing \\
\hline & $\begin{array}{l}\text { Definition: Summarizes what has taken place; points out departures from agreed-on } \\
\text { goals; tries to bring the team back to the central issues; raises questions about the direc- } \\
\text { tion in which the team is heading. }\end{array}$ \\
\hline \multirow[t]{2}{*}{ Eval } & Evaluating/Critiquing \\
\hline & $\begin{array}{l}\text { Definition: Constructively analyzes the team's accomplishments according to some set of } \\
\text { standards; checks to see that consensus has been reached. }\end{array}$ \\
\hline \multirow[t]{2}{*}{ Enc } & Encouraging \\
\hline & $\begin{array}{l}\text { Definition: Praises, agrees with, and accepts the contributions of others; offers warmth, } \\
\text { solidarity, and recognition. }\end{array}$ \\
\hline $\operatorname{Recog}$ & Recognition Seeking \\
\hline Appr & Out-of-Context \\
\hline Innapr & Definition: Appropriate/inappropriate out-of-context behaviors \\
\hline \multirow[t]{2}{*}{ Ten Red } & Tension Reduction \\
\hline & Definition: Attempt to defuse a potentially explosive situation \\
\hline Other & Other \\
\hline
\end{tabular}


Table 3

Conflict Interaction Protocol

\begin{tabular}{|c|c|}
\hline Code & Name \\
\hline \multirow[t]{2}{*}{ Block } & Blocking \\
\hline & $\begin{array}{l}\text { Definition: Interferes with progress by rejecting ideas or taking a negative stand on any and } \\
\text { all issues; refuses to cooperate. }\end{array}$ \\
\hline \multirow[t]{2}{*}{ Aggr } & Aggressive behaviors \\
\hline & Definition: Struggles for status by deflating the status of others; boasts; criticizes. \\
\hline \multirow{2}{*}{ Dom } & Dominating behaviors \\
\hline & $\begin{array}{l}\text { Definition: Interrupts and embarks on long monologues; is authoritative; tries to monopolize } \\
\text { the team's time. }\end{array}$ \\
\hline \multirow[t]{2}{*}{ Yield } & Yielding \\
\hline & $\begin{array}{l}\text { Definition: Accepting and incorporating the other's will, involves unilateral concessions, } \\
\text { unconditional promises, and offering help. }\end{array}$ \\
\hline \multirow[t]{2}{*}{ Avoid } & Avoiding/Withdraw \\
\hline & $\begin{array}{l}\text { Definition: Involves a passive stance, is aimed at reducing and downplaying the importance } \\
\text { of the conflict issues and at suppressing thinking about them. }\end{array}$ \\
\hline \multirow[t]{2}{*}{ Collab } & Collaborating \\
\hline & $\begin{array}{l}\text { Definition: Collaborating and problem solving. Achieving an agreement that satisfies both } \\
\text { one's own and the others' aspirations as much as possible. }\end{array}$ \\
\hline \multirow[t]{2}{*}{ Harm } & Harmonizing (from neutral individuals) \\
\hline & $\begin{array}{l}\text { Definition: Reconciles disagreements; mediates differences; reduces tensions by giving } \\
\text { team members a chance to explore their differences. }\end{array}$ \\
\hline 3rd-A & Third party help \\
\hline 3rd-B & $\begin{array}{l}\text { Definition: Seeking help from third party. Involving an outsider to settle a conflict; a distinc- } \\
\text { tion is made between third parties with process control such as a mediator and more auto- } \\
\text { cratic third parties with decision control, such as an arbiter. }\end{array}$ \\
\hline \multirow{2}{*}{ Main } & Maintenance \\
\hline & $\begin{array}{l}\text { Definition: A decision to maintain the status quo by avoiding or deferring action on differing } \\
\text { views. Constructive as an interim strategy. }\end{array}$ \\
\hline \multirow[t]{2}{*}{ Sup } & Supportive Release \\
\hline & $\begin{array}{l}\text { Definition: Even though one disagrees with their opponent's viewpoint, they unilaterally de- } \\
\text { cide to support and encourage this view within stipulated limits or conditions. }\end{array}$ \\
\hline
\end{tabular}

petitions, and inflexibility. When a conflict spirals out of control, it runs the risk of becoming destructive. When this happens, participants lose sight of their initial goals and focus on hurting the adversary.

\section{Task, Process, and Relationship Conflict}

Pinkley (1990) discovered that there is a task-versusrelationship dimension of conflict; this dichotomy has subsequently attracted the attention of other researchers working in the area of team dynamics. This division between task and relationship conflict leads to different predictions about the effect of conflict on team outcomes. A third type of conflict was uncovered by Jehn (Jehn, Northcraft, \& Neale, 1999; Jehn \& Shah, 1997) and is labeled process conflict. What follows is a description of each of these forms of conflict.

Task conflict is an awareness of differences and viewpoints pertaining to specific team tasks (Giebels, Janssen, Van de Vliert, \& Nauta, 1999; Jehn, 1997b; Jehn \& Chatman, 2000). It involves differences in viewpoints, ideas, and opinions. Examples are conflicts about the distribution of resources, procedures or guidelines, and the interpretation of facts. This type of conflict is said to be void of negative interpersonal emotions that are more commonly associated with relationship conflict.

Process conflict involves differences of opinion about how task accomplishment should proceed (Jackson, Johnson, Peterson, \& Trochim, 2002; Jehn, 1995). Process conflict pertains to issues of duty and resource delegation, such as who should do what or how much work one should get. When team members disagree about whose responsibility it is to complete a specific duty, they are experiencing process conflict.

Relationship conflict has been found to be particularly damaging because of its interpersonal emotional nature (De Dreu, 1997; De Dreu \& van Vianen, 2001; De Dreu \& Weingart, 2003; Giebels \& Janssen, 2005; Jehn, 1992). Relationship conflict relates to personal issues, such as dislikes and differences over attitudes, norms and values, personality, and political beliefs. It is characterized by feelings such as annoyance, frustration, and irritation.

\section{Development of the Protocols}

In order to address the question of how conflict affects the performance of SE teams, data were collected using three different classification typologies of behaviors. The first two classifications consist of a conflict and social interaction protocol and were used to capture events or utterances made during discussions. The third was designed to capture sets of utterances that describe the conflicts observed. The third classification consists of three different typologies that aim to record the type of conflict, any mutation, and the outcome of the conflict. These data were linked to performance measures that were collected independently.

In order to understand the timing of conflict as well as to be able to identify changes in the processes and frameworks of the team, a social interaction protocol (see Table 1) was developed. The social interaction protocol is loosely based on previous work that looked at the func- 
Table 4

Conflict Type

\begin{tabular}{ll}
\hline Code & Conflict Type \\
\hline Task & Task \\
Pro & Process \\
Rel & Relationship \\
\hline
\end{tabular}

tional roles of team members (Benne \& Sheats, 1948), which were then transformed to capture interactions among individuals.

The conflict interaction protocol is based on the work of Blake and Mouton (1964). This work was transformed from the conflict level to account for the interactions at the individual and team level. The conflict interaction protocol includes behaviors that occur during conflict episodes as identified by Pruitt and Ruben (1986): contending, conceding, avoiding, and collaborating. In addition, other forms of conflict interaction-such as blocking, harmonizing, and the notion of supportive release-were also added to create an exhaustive list that allowed researchers to record with greater accuracy the development of conflict and how team members reacted to it.

\section{Conflict Type, Mutation Outcome, and Intensity}

A third typology (see Table 4) was used to capture the type of conflict, task, process, or relationship. There is a fifth typology (see Table 5) that aims to capture mutations from one type of conflict to another. Using this typology, a mutation - that is, task to relationship - would be represented as T $>$ R. Finally, there is a list of conflict outcomes (see Table 6) that was proposed by project researchers. The outcomes range from agreement between team members to team members being browbeaten into submission. Again, codes are used - that is, "agreement" becomes "AGG," and "browbeaten" becomes "brow." If no agreement can be reached, then the conflict remains unresolved.

The intensity of a conflict was measured by recording the number of utterances made during each conflict episode. The frequency was simply how many occurrences there were of a specific form of a conflict across the research period.

\section{Research Environment and Subjects}

The context for this study is the Software Engineering Observatory at the University of Sheffield, a research facility that enables researchers to observe, question, and interview developers working on projects for real clients. The observatory has a range of projects from "Crossover" - a first-year undergraduate-level course - to MSc-level projects, such as Maxi and Genesys.

Table 5

Mutation

\begin{tabular}{ll}
\hline Code & \multicolumn{1}{c}{ Mutation Type } \\
\hline $\mathrm{T} \rightarrow \mathrm{P}$ & Task to process \\
$\mathrm{T} \rightarrow \mathrm{R}$ & Task to relationship \\
$\mathrm{P} \rightarrow \mathrm{T}$ & Process to task \\
$\mathrm{P} \rightarrow \mathrm{R}$ & Process to relationship \\
$\mathrm{R} \rightarrow \mathrm{T}$ & Relationship to task \\
$\mathrm{R} \rightarrow \mathrm{P}$ & Relationship to process \\
\hline
\end{tabular}

Three Maxi teams were observed during this study. Generally speaking, the manager of the Maxi project instructs the teams to follow the Waterfall methodology, which has been described in detail in several standard SE texts (e.g., Pfleeger, 2001; Pressman, 2001; Sommerville, 2004). Teams adhering to this methodology progress in a linear fashion through each stage in the SE life cycle (feasibility, analysis, design, implementation, and testing). In this year's Maxi project, the clients were from the University of Sheffield Dental School and the English Language Teaching Center at the University of Sheffield, which is responsible for improving the spoken and written English skills of overseas students. The dental school wanted a software package to help them to keep track of how many students were posted at different locations on the basis of the course they were studying, how many dental chairs were required, how many students could be placed in a particular block (a training period, a placement at a particular location required for a specific course for a certain amount of time), whether it would be possible to place students in their preferred blocks, and which members of staff would be responsible for each placement. The English Language Teaching Center required software that would enable them to track which dyslexic students had enrolled for each course, along with their progress, any appointments they had made, their personal tutor, and whether they had completed any courses.

As for the teams themselves, they had an interesting makeup, with over $65 \%$ of the students having an Asian background (the overwhelming majority [82\%] of the Asian students were Chinese). Only $18 \%$ of the students were native English speakers, and one team did not include a single native English speaker. Another noteworthy factor is that the native English speakers were all mature students.

In addition to the demographic diversity, the students were diverse in their levels of skill and experience. Some of the students had a background in SE, whereas others came from technical backgrounds (such as mechanical engineering) or from the social sciences. Finally, at the start of the academic year, there were four Maxi teams. After a month or so, a dysfunctional team was disbanded by the manager, and its members were dispersed into the remaining three teams. Therefore, the teams had the problem of incorporating and adjusting to new members a month into the project. Such factors have to be taken into account when looking at how conflict affects the performance of teams.

\section{RESULTS}

\section{Team A}

This team experienced the most intensive, the greatest frequency of, and the highest number of unresolved conflicts, and they were the poorest performing team. They experienced a total of 51 conflicts during meetings throughout the feasibility, analysis, and design phases. Most of the conflicts (41) were task conflicts, with 10 process conflicts and no relationship conflicts (see Table 7).

Some of the task conflicts involving members of this team included how to proceed with the project. The crux of 
Table 6

Outcome

\begin{tabular}{lll}
\hline Code & \multicolumn{1}{c}{ Name } & \multicolumn{1}{c}{ Description } \\
\hline AGG & Agreement & Amicable agreement reached between protagonists \\
Unres & Unresolved & Conflict remains unresolved \\
Agdi & Agree to disagree & Protagonists agree to disagree \\
Brow & Browbeaten & One protagonist browbeats the other into submission \\
\hline
\end{tabular}

this debate was whether to adopt a parsimonious approach aiming to please the client and grinding out a result, or to employ a flamboyant, sophisticated approach by giving the team's imagination and creative abilities free rein. The subjects of other debates included transferring data from an existing database, risks, the layout of the feasibility report, Unified Modeling Language (UML) and other notations, business options, and users of the final system.

The process conflicts ranged from opinions on who had the most knowledge of programming languages and could do most of the programming to working arrangements (whether to work at home or in the lab), collecting the statistics for each stage, and arranging meetings with the client.

There was a lack of any ad hominem sniping or strawman argumentation; hence, there were no relationship conflicts between members of this team. Even though this team did not have any personal conflicts, they suffered because of the high frequency and intensity of the conflicts over the research period.

Many of the conflicts were of an intense nature and involved many utterances between two or more team members. Due to the high levels of intensity, a lot of time and energy was spent debating certain issues. Another problem was the high number of conflicts that remained unresolved. This was even more damaging if it was a particularly intensive issue. In total, $42 \%$ of task conflicts-including the structure of the database, completing the project, and hardware and software constraints-were unresolved. An even higher proportion of process conflicts- $40 \%$ remained unresolved. Some of these were important issues, such as deciding who would be the main programmers, incorporating new members into the team, and when to arrange a meeting with the client. Because these issues were left unresolved, there was confusion about when to meet the client, with some members arguing for regular meetings and others saying that they should only meet when the team had made sufficient progress. Time was wasted trying to incorporate the new members; if they had been given work to do at the earliest opportunity, their assimilation into the team would have been less problematic.

\section{Team B}

Team B was the highest performing team in terms of the grades of the three Maxi teams observed (see Table 8). They also had a much higher percentage of resolved task conflicts than did either of the other teams ( $83 \%$ as opposed to $58 \%$ for Team A). In comparison with Team A, which had 41 task conflicts, Team B had a lower frequency of task conflicts, with only 23 . They each had 3 relationship conflicts and similar numbers of process conflicts. All of the relationship conflicts were successfully resolved.
Some of the task conflicts involving this team included getting the requirements document right the first time, organizational constraints, using UML for activities, grading the requirements (by importance), what to do if they could not meet certain requirements, and the availability of the system - that is, how much downtime is reasonable. The unresolved task conflicts were not particularly damaging. They included whether the whole team should sign the budget for Stage 1, and whether to use UML or Structured Systems Analysis and Design Method.

The process conflicts revolved around issues such as deciding who would manage the different stages, arranging meetings with the client, and integrating new members into the team. Some $31 \%$ of process conflicts were unresolved. One conflict was due to a team member's personal values interfering with the work (he felt that constraints from the client or manager would serve to restrict the intellectual freedom of the team). He would have been responsible for doing most of the programming and deciding whether the client would sanitize data before sending them to the team.

The relationship conflicts were not personal attacks on team members; they were caused by political disagreements. Disagreements took place on the subjects of global capitalism, the role of large corporations, and Microsoft. One member was pro-Microsoft, whereas another member of the team wasn't so enthusiastic. However, the relationship conflicts were not damaging, since no one used harsh or sarcastic language to attack or ridicule another team member.

A contributing factor to the good performance of this team was that the conflicts they experienced were generally of a low intensity, and most were resolved in a satisfactory manner. Members of this team attempted to settle task conflicts by means of negotiation. However, occasionally, if a conflict was going on for too long, with no agreement in sight, then one member of the team would force his or her opinion through. Several conflicts were resolved by someone browbeating an opponent into acquiescence. In one example, a team member was discussing the writing style in the requirements document, stat-

Table 7

\section{Team A Conflict Data}

\begin{tabular}{cccccc}
\hline $\begin{array}{c}\text { Conflict } \\
\text { Type }\end{array}$ & $\begin{array}{c}\text { No. of } \\
\text { Conflicts }\end{array}$ & $\begin{array}{c}\text { Intensity } \\
\text { (Utterances) }\end{array}$ & Resolved & Unresolved & Perform. \\
\hline $\mathrm{T}$ & 41 & 139 & $58 \%$ & $42 \%$ & $111 / 177$ \\
$\mathrm{P}$ & 10 & 40 & $60 \%$ & $40 \%$ & \\
$\mathrm{R}$ & 0 & & & & \\
\hline
\end{tabular}

Note- T, task; P, process; R, relationship. 
Table 8

Team B Conflict Data

\begin{tabular}{cccccc}
\hline $\begin{array}{c}\text { Conflict } \\
\text { Type }\end{array}$ & $\begin{array}{c}\text { No. of } \\
\text { Conflicts }\end{array}$ & $\begin{array}{c}\text { Intensity } \\
\text { (Utterances) }\end{array}$ & Resolved & Unresolved & Perform. \\
\hline $\mathrm{T}$ & 23 & 90 & $83 \%$ & $17 \%$ & $136 / 177$ \\
$\mathrm{P}$ & 13 & 59 & $69 \%$ & $31 \%$ & \\
$\mathrm{R}$ & 3 & 11 & $100 \%$ & & \\
\hline
\end{tabular}

Note-T, task; P, process; R, relationship.

ing that it didn't flow or read easily. The response to this criticism was an instruction to "hammer home why the system is justified, don't imply it." Another disagreement revolved around using UML versus Data Flow Diagrams (DFDs), and it was brought to a halt by a team member making a strong statement that UML was widely used in the industry and that it would be trouble free to annotate the UML notations as well as justify the choice. Particularly for task conflicts, the team was anxious to resolve the issue there and then; doing so allowed them to move on to the next duty.

Because of the nature of some of the process conflictsfor example, whether to arrange meetings over the weekend, to schedule extra meetings with the client, and to work over the weekend - it was impossible to resolve them successfully. Other commitments and time constraints also factored into this difficulty.

The incorporation of new members into Team B was not as problematic as it was for Team A. The new members were quickly brought up to speed and were assigned tasks in a no-nonsense manner. There was little questioning from the new members, and, by and large, they accepted their roles on the team.

\section{Team C}

Team $C$ experienced the least intense and the lowest frequency of conflicts. In comparison with the other teams, they had very few task conflicts, a similar number of process conflicts, and no relationship conflicts. In terms of performance, they were the middle team. An interesting outcome was that they had an almost equal number of task and process conflicts (see Table 9).

Some of the major task conflicts experienced by this team included disagreements about the budget calculations for a particular stage, whether to use Java or Microsoft Access to implement the system, whether to stress either all of the requirements in the requirements document or only those seen to be essential, the effective use of change notes (should they be unable to meet certain requirements), and how thoroughly the system should be tested.

The team managed to resolve $60 \%$ of process conflicts. Examples of those successfully resolved included team members spending time to create a realistic budget for each stage, and whether to spend time learning another methodology instead of using the "Waterfall" method (the decision reached was in favor of the Waterfall method). Among those unresolved were issues such as walking away if the client was being unrealistic with his expectations, how to reassign tasks to the new members in the team, and new members requiring further explanation in relation to certain tasks.

Although this team experienced the least number of conflicts, they were not the highest performing team. This result is worth examining in more detail. On the positive side, they did not have to expend so much energy during intense conflicts in the way Team A did. This meant that there was less strain on the relationships between team members. The team could also spend more time working rather than going around in circles debating or trying to score points against each other. On the negative side, the low number of task conflicts was symptomatic of a deeper problem. This problem was the fact that issues were not debated and that sometimes team members were moving in opposite directions, unaware of the current positions of other people on the team. It must be added, however, that the leading members of this team were hard workers. Nonetheless, a very dangerous situation can arise when individuals are reluctant to express opinions about something of concern either because no one else has mentioned it or because they lack the assertiveness to put the point forward.

\section{DISCUSSION}

This project involved observing and recording the conflict episodes that took place in three SE projects and developing a template to aid with this task. The results show that the highest performing team was the one that experienced "moderate" levels of task conflict in comparison with the other teams. This finding is in line with previous research (Amason, 1996; Amason \& Sapienza, 1997; Jehn, 1992, 1995, 1997b; Pinkley, 1990), the findings of which can be summarized as follows: Task conflict can be beneficial; it is positively related to the quality of ideas; and it increases levels of constructive debate.

Although there is some agreement that teams need to engage in some task conflicts to produce high-quality decisions, if these conflicts are too frequent and highly intensive, then grave troubles can occur. Findings show that excessive task conflict can interfere with consensus and hinder the implementation of ideas (Schweiger \& Sandberg, 1989), that task conflict might be as negative as relationship conflict and could have a pernicious effect as it increases intensity and stress (De Dreu \& Weingart, 2003), and, finally, that incessant task conflict can lead to emotional exhaustion and is inextricably bound up with psychic tension and stress (Giebels \& Janssen, 2005).

There are also arguments against too little task conflict. Some of the findings suggest both that low levels of this

\begin{tabular}{cccccc}
\multicolumn{6}{c}{ Table 9 } \\
\multicolumn{7}{c}{ Team C Conflict Data } \\
\hline $\begin{array}{c}\text { Conflict } \\
\text { Type }\end{array}$ & $\begin{array}{c}\text { No. of } \\
\text { Conflicts }\end{array}$ & $\begin{array}{c}\text { Intensity } \\
\text { (Utterances) }\end{array}$ & Resolved & Unresolved & Perform. \\
\hline $\mathrm{T}$ & 14 & 42 & $71 \%$ & $29 \%$ & $122 / 177$ \\
$\mathrm{P}$ & 13 & 33 & $60 \%$ & $40 \%$ & \\
$\mathrm{R}$ & & & & & \\
\hline
\end{tabular}

Note- $\mathrm{T}$, task; P, process; R, relationship. 
form of conflict will result in inactivity because teams lack a sense of urgency (Van de Vliert \& De Dreu, 1994) and that a moderate level of task conflict is necessary if a team is to produce high-quality decisions (see, e.g., Giebels et al., 1999; Jehn, 1995, 1997a; Jehn \& Shah, 1997; Simons \& Peterson, 2000).

This research has looked at conflict in SE teams; other researchers have focused on conflict in other contexts. The results from this study are similar to those found in the other SE studies of conflict. The researchers who carried out the previous SE studies (Elam \& Walz, 1988; Gobeli, Koenig, \& Bechinger, 1998; P. Sawyer et al., 1999; S. Sawyer, 2001) concluded that SE environments should not be conflict free; rather, they should be conflict managed. The final verdict one reaches after reading the aforementioned articles is that conflict per se is not intrinsically good or evil; the key factors are the form and frequency and the effectiveness of conflict-management strategies.

An important contribution of the present study was the development of the social and conflict interaction protocols and the subsequent creation of a template based on them. If used effectively, the template allows researchers to capture detailed descriptive data about the conflict episodes that take place within teams. The template expands on the work of Elam and Walz (1988) by giving focus to the form of conflict, the intensity, and whether and how it was resolved.

\section{CONCLUSION}

This project involved carrying out a detailed study of three SE teams and recording their conflict experiences. Because of the nature of the study, one outcome was a fascinating insider's view of how members of SE teams initiate, behave during, and resolve conflict episodes. By observing and inquiring about the research subjects' normal activities throughout their specific projects, the researchers were able to gain an empathic and realistic understanding of this particular social scene. The use of observational methods allowed one to trace conflicts from their inception to their conclusion and to see firsthand the effects of different forms of conflict.

The conflict template that was created to capture data for this study allowed the researcher to collect the data in a consistent and reliable way. The template allowed the recording of interactions: who spoke to whom, how they spoke (e.g., opinion giving or asking for an opinion), the form of conflict, whether it mutated, and how it was resolved. It also provided space for a detailed description of the events that were taking place. The interactions were recorded, even if they progressed in a nonlinear manner. It is hoped that this way of recording and analyzing conflict episodes in teams will encourage other researchers to use and perhaps expand the template used during this study. If using this template will lead to a greater understanding of how conflict can either help a team to grow or destroy it from within, then it will serve an important purpose for the wider SE community, since team members must be able to work together effectively in order to maximize their potential.

\section{AUTHOR NOTE}

Correspondence concerning this article should be addressed to J. S. Karn, Department of Computer Science, University of Sheffield, Sheffield S1 4DP, England (e-mail: j.karn@sheffield.ac.uk).

\section{REFERENCES}

Amason, A. C. (1996). Distinguishing the effect of functional and dysfunctional conflict on strategic decision making: Resolving a paradox for top management teams. Academy of Management Journal, 39, 235-245.

Amason, A. C., \& SAPIEnZA, H. (1997). The effects of top management team size and interaction norms on cognitive and affective conflict. Journal of Management, 23, 495-516.

Amason, A. C., \& Schweiger, D. (1994). Resolving the paradox of conflict, strategic decision making, and organizational performance. International Journal of Conflict Management, 5, 239-253.

BenNe, K. D., \& Sheats, P. (1948). Functional roles of group members. Journal of Social Issues, 4, 41-49.

Blake, R. R., \& Mouton, J. S. (1964). The managerial grid: The key to leadership excellence. Houston: Gulf Publishing.

CoHEN, G. S., \& BAILEY, E. D. (1997). What makes teams work: Group effectiveness research from the shop floor to the executive suite. Journal of Management, 23, 239-290.

Crowston, K., \& Kammerer, E. E. (1998a). Collective mind in software requirements development. IBM Systems Journal, 36, 1-24.

Crowston, K., \& Kammerer, E. E. (1998b). Coordination and collective mind in software requirements development. IBM Systems Journal, 37, 227-245.

CURTIS, B. (1991). Techies as non-technological factors in software engineering. In Proceedings of the 13th International Conference on Software Engineering (pp. 147-148). Los Alamitos, CA: IEEE Computer Society Press.

CURTIS, B. (1998). Which comes first, the organization or its processes? IEEE Software, 15, 10-13.

Curtis, B., Krasner, H., \& Iscoe, N. (1988). A field study of the software design process for large systems. Communications of the ACM, 31, 227-245.

Curtis, B., Walz, D. B., \& Elam, J. J. (1993). Inside a software design team: Knowledge acquisition, sharing, and integration. Communications of the ACM, 36, 63-77.

Darling, J. R., \& Walker, W. E. (2001). Effective conflict management: Use of the behavioural style model. Leadership \& Organization Development Journal, 22, 230-242.

De Dreu, C. K. W. (1997). Productive conflict: The importance of conflict management and conflict issues. In C. K. W. De Dreu \& E. Van de Vliert (Eds.), Using conflict in organizations (pp. 9-23). London: Sage.

De Dreu, C. K. W., van Dierendonck, D., \& De Best-Waldhober, M. (2005). Conflict at work and individual well-being. In M. J. Schabracq, J. A. M. Winnubst, \& C. L. Cooper (Eds.), Handbook of work and health psychology (2nd ed., pp. 495-515). New York: Wiley.

De Dreu, C. K. W., \& van Vianen, A. E. M. (2001). Managing relationship conflict and the effectiveness of organizational teams. Journal of Organizational Behavior, 22, 309-328.

De Dreu, C. K. W., \& Weingart, L. R. (2003). Task versus relationship conflict, team performance and team member satisfaction: A metaanalysis. Journal of Applied Psychology, 88, 741-749.

DesiviLYA, H. S. (1998). Using conflict in organizations. International Journal of Conflict Management, 9, 369-376.

DeuTsch, M. (1949a). An experimental study of the effects of cooperation and competition upon group process. Human Relations, 2, 199-231.

Deutsch, M. (1949b). A theory of cooperation and competition. Human Relations, 2, 129-152.

Deutsch, M. (1973). The resolution of conflict: Constructive and destructive processes. New Haven, CT: Yale University Press.

Elam, J. J., \& Walz, D. B. (1988). A study of conflict in group design activities: Implications for computer-supported cooperative environments. In Proceedings of the 21st Annual Hawaii International Conference on Decision Support and Knowledge Based Systems Track (pp. 247-254). Los Alamitos, CA: IEEE Computer Society Press.

GaLINSKY, A. (2002). Creating and reducing intergroup conflict: The 
role of perspective taking in affecting out-group evaluations. Toward Phenomenology of Groups and Group Membership, 4, 85-113.

Giebels, E., \& Janssen, O. (2005). Conflict stress and reduced wellbeing at work: The buffering effect of third-party help. European Journal of Work \& Organizational Psychology, 14, 137-155.

Giebels, E., Janssen, O., Van de Vliert, E., \& Nauta, A. (1999). Constructive conflict at work. Journal of Organizational Behavior, 20, 475-491.

Gobeli, D. H., Koenig, H. F., \& Bechinger, I. (1998). Managing conflict in software development teams: A multilevel analysis. Journal of Product Innovation Management, 15, 423-435.

HARRIS, F. C., \& LoONEY, C. G. (1999). Strategies for effective group project based courses. In B. J. O'Toole (Ed.), Proceedings of the ASEE-PSW Conference (pp. 59-66). Las Vegas, NV.

Jackson, K. M., Johnson, S. C., Peterson, R. S., \& Trochim, W. M. K. (2002, June). A multi-faceted approach to process conflict. Paper presented at the 15th Annual Conference of the International Association for Conflict Management, Salt Lake City, UT.

JEHN, K. A. (1992). The impact of intragroup conflict on effectiveness: A multi-method examination of the benefits and detriments of conflict. Unpublished doctoral dissertation, Northwestern University, Evanston, IL.

JEHN, K. A. (1995). A multimethod examination of the benefits and detriments of intragroup conflict. Administrative Science Quarterly, $\mathbf{4 0}$ 256-282.

JEHN, K. A. (1997a). Affective and cognitive conflict in work groups: Increasing performance through value based intra-group conflict. In C. K. W. De Dreu \& E. Van de Vliert (Eds.), Using conflict in organizations (pp. 87-100). Beverly Hills: Sage.

JEHN, K. A. (1997b). A qualitative analysis of conflict types and dimensions in organizational groups. Administrative Science Quarterly, $\mathbf{4 2}$, 530-557.

Jehn, K. A., \& Chatman, J. A. (2000). The influence of proportional and perceptual conflict composition on team performance. International Journal of Conflict Management, 11, 741-763.

Jehn, K. A., Northcraft, G., \& Neale, M. A. (1999). Why difference makes a difference: A field study of diversity, conflict, and performance in work groups. Administrative Science Quarterly, 44, 741-763.

JeHN, K. A., \& SнAH, P. (1997). Interpersonal relationships and task performance: An examination of mediating processes in friendship and acquaintance groups. Journal of Personality \& Social Psychology, 72, 775-790

Johnson, D. W., \& Johnson, R. T. (1978). Cooperative, competitive, and individualistic learning. Journal of Research \& Development in Education, 12, 3-15.

Pelled, L. H. (1996). Demographic diversity, conflict, and work group outcomes: An intervening process theory. Organizational Science, $\mathbf{6}$, $615-631$
Pelled, L. H., Eisenhardt, K. M., \& Xin, K. R. (1999). Exploring the black box: An analysis of work group diversity, conflict, and performance. Administrative Science Quarterly, 44, 1-28.

Petre, M., Budgen, D., \& Scholtz, J. (2004). A focus on the human side of software engineering. Empirical Software Engineering, 9, 32-37.

Pfleeger, S. L. (2001). Software engineering: Theory and practice (2nd ed.). Upper Saddle River, NJ: Prentice Hall.

PinKLEY, R. L. (1990). Dimensions of conflict frame: Disputant interpretations of conflict. Journal of Applied Psychology, 75, 117-126.

Pressman, R. S. (2001). Software engineering: A practitioner's approach (5th ed.). Boston: McGraw Hill.

PruitT, D. G., \& Rubin, J. Z. (1986). Social conflict: Escalation, stalemate, and settlement. New York: Random House.

RobBins, S. P. (1989). Organizational behavior: Concepts, controversies and applications. Englewood Cliffs, NJ: Prentice Hall.

Rognes, J. (1998). Are cooperative goals necessary for constructive conflict processes? Applied Psychology, 3, 331-336.

SaWyer, P., Sommerville, I., \& Viller, S. (1999). Capturing the benefits of requirements engineering. IEEE Software, 16, 78-85.

SAWYER, S. (2001). Effects of intra-group conflict on packaged software development team performance. Information Systems Journal, 11, 155-178.

SchWeIGER, D., \& SANDBERG, W. (1989). The utilization of individual capabilities in group approaches to strategic decision making. Strategic Management Journal, 10, 31-43.

Simons, T. L., \& Peterson, R. S. (2000). Task conflict and relationship in top management teams: The pivotal role of intragroup trust. Journal of Applied Psychology, 85, 102-111.

Sommerville, I. (2004). Software engineering (7th ed.). Menlo Park, CA: Addison Wesley.

TJosvold, D. (1991). Rights and responsibilities of dissent: Cooperative conflict. Employee Responsibilities \& Rights Journal, 4, 13-23.

TJosvold, D. (1997). Conflict within interdependence: Its value for productivity and individuality. In C. K. W. De Dreu \& E. Van de Vliert (Eds.), Using conflict in organizations (pp. 23-37). Thousand Oaks, CA: Sage.

Tuosvold, D., Hui, C., \& LaW, K. S. (2001). Constructive conflict in China: Cooperative conflict as a bridge between East and West. Journal of World Business, 36, 166-183.

Van de Vliert, E., \& De Dreu, C. K. W. (1994). Optimizing performance by conflict stimulation. International Journal of Conflict Management, 5, 211-222.

WILMOT, W. W., \& HOCKER, J. L. (2001). Interpersonal conflict (6th ed.). New York: McGraw Hill.

(Manuscript received July 30, 2007; revision accepted for publication October 9, 2007.) 